\title{
Landmines: A Threat to Sustainable Development
}

\author{
Imtiaz Ahmed* \\ *The author is Senior Research Fellow, Department of Strategic and Regional Studies (DSRS), University of \\ Jaтmu, Јатти and Kashmir, India-180006.
}

\begin{abstract}
Landmines are one of the most environmentally destructive aftermaths of war facing the world today. The global landmine problem has transcended both humanitarian and sociological concerns to bring about environmental damage. Disruption of land's stability, pollution and loss of biodiversity constitute major ecological repercussions of landmine crisis. This paper aim to emphasise how landmines are having devastating impact on economy, led to loss of biodiversity, ecological crisis, soil contamination, loss of productivity, threat to food security, community health, poverty and social marginalisation. Landmines are threat to sustainable development as all above issues are interlinked. Its contamination led to under-development of nation because of access denial to utilise natural resources like water, forest, land etc. Excessively intensive cultivation, overgrazing and deforestation in the mine free lands led to ecological imbalance. Landmines cause refugee and internal displacement problem. They terrorize and demoralize civil society as well. Their impact on the fragile health system of the country where they have been used in greater number can be overwhelming. The threat of mines hinders relief operations by preventing access to certain areas by aid agencies, disrupting road networks and necessitating the implementation of landmine clearance operations which are vastly expensive both in financial and human terms A simple mine cost less than $\$ 3$, its clearance however requires $\$ 300$ to $\$ 1000$ making demining a very costly and slow process.
\end{abstract}

Key words: Anti-personnel landmines (APLs), Humanitarian crisis, Other Explosive Devices (OED), Non Governmental Organisations (NGOs), Demilitarized Zone (DMZ)

\section{Introduction}

Sustainable development is 'development that meets the current needs without compromising the ability of future generations to meet their own needs'. Development as a concept is multidimensional; encompassing ecologic, economic, social, and political attribute of a system. Sustainable development principles then advocate a process of change in which resource use, investment directions, orientation of technological advances and associated institutional changes endeavour to accommodate the needs of present and future generations by looking beyond narrow, conventional solutions to social and environmental problems in order to address them from a broad, comprehensive perspective.

The wide use of APLs has created a global humanitarian and ecological crisis. Attempts to estimate the number of AP mines in the ground around the world have been made by countries reporting under the Ottawa Convention. But counting the number of mines in the ground does not accurately measure the problems that landmines cause.

The most meaningful measure of landmines' effects is the amount of high priority land where mines are hidden. This land could be farmed, is socially and economically valuable, or is vital to the movements of people nearby. Risk of death or injury limits its use, and the community cannot use a field whether it hides two mines or 10,000. For example, in 1996, Norwegian Peoples Aid cleared a village in Mozambique after it had been abandoned by the entire population of around 10,000 villagers due to alleged mine infestation. After three months of work, the deminers found four mines. Four mines had denied the people access to their homes and land and caused the dislocation of 10,000 people. Any attempt to count the number of mines laid around the world can only be an estimate, so mine action groups now focus on the humanitarian crises that landmines cause.

The deadly seriousness of the landmine story is in the numbers of people affected by landmines, especially the estimated tens of thousands of new direct and indirect victims each year. Landmines cause huge barriers to social and economic development in some of the world's poorest countries. Since 1975, there are estimated to have been more than a million landmine casualties most civilians, many children. Landmines that do not kill immediately severely maim their victims, causing trauma, lifelong pain and often, social rejection. Worldwide, some 300,000 to 400,000 landmine survivors face terrible physical, psychological and socioeconomic difficulties.

Landmines have been called a global public health crisis by Jody Williams. In Cambodia along with Malaria and Tuberculosis; landmines have ranked as one of the three most public health crisis. In Afghanistan, 
landmines claim between 20-25 victims a day. Of these 8000 victims annually 4000 survive. At an estimated 5000 dollars per victim for rehabilitation, the direct cost for survivors of landmines incidents in that country alone is $\$ 20$ million annually.

These figures are not unique to Cambodia and Afghanistan. They could be replicated for many of countries contaminated by landmines in the world today. It is estimated that 80-110 million landmines are sown in 64 countries around the world. Another 100 million are stockpiled and ready for use. At least 500 peoples are victim of landmines each week. The current estimate of landmine disabled population globally is 250000 .

Often designed to maim rather kill, their psychological impact on the enemies undeniable. In addition to demoralizing the opposition landmines causalities can also overload its logistical support system. Most mine victims require extensive medical and rehabilitative attention than other types of war related casualties. Yet landmines do not discriminate between the logistical support system of military and that of society as whole. They terrorize and demoralize civil society as well. Their impact on the fragile health system of the country where they have been used in greater number can be overwhelming. Post conflict landmines related casualties are also exclusively civilian.

The impact of landmines extends beyond just health systems. When much of a country has become theatre of battle as with Afghanistan, Angola, Cambodia, Mozambique, Somalia, the former Yugoslavia and list goes on little is left untouched. Used offensively, landmines have been deployed to depopulate areas, to disrupt agriculture and to interpret flow of goods and services, transport system are affected, power systems are effected, agriculture and grazing lands are affected, religious sites are affected, national parks and forests are affected, villages and people living in them are fleeing from them are affected. In short all that make fabric of nation can be contaminated by landmines. Unlike other weapons of war, landmines and Other Explosive Devices (OED) that act as landmines, recognize no peace agreement. They continue to kill and maim for decades.

Mines are arguably the most toxic and widespread pollution facing mankind. The deleterious economic effect of landmines are the loss of accessible and arable land, inaccessible water supply, strain on health system, loss of productive labour, inhibition of the repatriation of refugees and obstruction to economic development. The effect of landmines on the land may last more than 100 years particularly because of fear of population entering in the area known to contain landmine. For example; it is estimated that agricultural production in Cambodia and Afghanistan can be doubled if all landmines are removed from these countries.

\section{The economic impacts are:}

- Farmer lost their crops there by threat to food security and survival.

- Farmer observed that mine fields decline the fertility of land due to growth of weeds and lack of irrigation.

- The number of rodents (rats) also multiplies causing damage to agricultural land.

- The domestic animals also become victim of landmines, which are back boon of agriculture and pastoral economy.

- APLs denied access to natural resources like land, forest, water resources etc.

\section{The Social Impacts are:}

- The vast majority of victims are civilians and not soldiers.

- It is not just during conflict, most of the countries where casualties are reported are at peace.

- Landmines victims become burden on family and society.

- The married women victims are often divorced by their husbands and unmarried girls' chances of getting married are very less.

- If bread winner of family become victim of landmine, whole family suffers.

\section{Economic impact}

\section{Categorization of Landmine Effects}

On the wider scale, the health care systems of countries with a landmine problem are severely stretched. Many countries do not have enough trained surgeons to cope with the workload. This results in inadequate treatment of the wounds and subsequent additional mortality and long term disability from amputation stumps that will not support prosthesis. Victims of anti-personnel mines account for 25 percent of the war injuries seen in hospitals. Of the landmine injured, 85 percent require amputations, and over 80 percent of the lower limb amputations performed as a result of all war related injuries is due to landmines. Landmine patients also require more blood transfusions, more surgical procedures per patient and remain in hospital longer than patients with gunshot or fragment injury, adding to the cost and requiring a disproportionately large amount of surgical time. Children often require stump revision as growing bone protrudes through the skin. There are an 
estimated 36,000 landmine amputees in Cambodia out of a population of 8.5 million, one in every 236 Cambodians has lost at least one limb to Landmines.

This represents a major public health and economic problem. Rehabilitation of patients involves a huge demand for artificial limbs. The cost of these devices is beyond the means of the majority of patients, and is largely borne by NGOs.

Prosthetic workshops have been established in areas of need, training local employees to manufacture limbs from locally available material to keep the costs down. In 1991, the ICRC workshops produced 7876 artificial limbs worldwide, the vast majority for landmine amputees. Despite these massive efforts, there is still a huge backlog of patients waiting for limb fitting. Handicapped International (HI) estimates that only one in eight Cambodian mines amputees have so far been fitted with artificial limbs. Replacement prosthesis is needed every 3-5 years for an adult and every 6 months by a child, ensuring that the costs will continue for decades to come. Use of local rubber and wood instead of more robust western synthetic materials means that although the prostheses can be produced cheaply, they have a shorter life span and require more frequent replacement. The cost of providing a 10 year old child with a lifetime of artificial legs is estimated by the Red Cross to be $\$ 3125$. Without postoperative support, physiotherapy and effective rehabilitation, saving the patient in the operating theatre merely condemns him to a life of misery.

Amputees in a peasant agrarian society become an unproductive burden on their families. Women amputees are less desirable as brides because they cannot work in the fields. The incidence of vagrancy and petty crime among amputees is thought to be higher than in the able bodied population. The threat of mines hinders relief operations by preventing access to certain areas by aid agencies, disrupting road networks and necessitating the implementation of landmine clearance operations which are vastly expensive both in financial and human terms. A simple mine cost less than $\$ 3$, its clearance however requires $\$ 300$ to $\$ 1000$ making demining a very costly and slow process. It costs $\$ 6000$ dollars per year to employ a local landmine clearer, and up to 30 times this figure to employ an expatriate demining expert to train and supervise the locals. In 1994, \$27 million was spent by the UN on mine clearance. Many areas are laboriously cleared, which yield a very small number of devices, but owing to the threat, every inch of the ground has to be assumed to be harbouring a mine until proved otherwise. Approximately one mine clearer is injured for every 2000 mines cleared. Despite all the effort and expense, mine clearing efforts are barely scratching the surface of the problem.

\section{Ecological dimensions}

The impacts of landmines on soil, flora and fauna, and people are felt at different levels of the ecological system, whether the mines have detonated or not. The ways in which landmines cause land degradation are broadly classified into five groups: access denial, loss of biodiversity, micro-relief disruption, chemical contamination, and loss of productivity Access denial. All the study pointed out that the most prominent ecological issue associated with landmines presence (or fear of) is access denial to vital resources. It is estimated that landmines have denied access to or degraded $900000 \mathrm{~km}^{2}$ of land, globally. For their military purpose, landmines guarantee that people and their movements are channelled away from strategically significant sites, and prevent military incursion. But the use of landmines is not by any means confined to military establishments or sites of military significance. The fear of presence of even a single landmine can deny people access to land that they desperately need for agriculture, water supply or to undertake conservation measures, and for technical teams engaged in pest control. Landmines are used in large quantities around arable lands in Lebanon, Angola, Mozambique, Cambodia; pasturelands in the Sinai, Kuwait and Iraq, forests in Nicaragua and the Demilitarized Zone (DMZ) between North and South Korea, coastal areas in Kuwait and Egypt, borders, infrastructures (bridges, roads, electrical installations, canals and water sources) and nearby commercial and public centres in Vietnam, Zimbabwe, Eritrea and Ethiopia, and residential areas in Serbia. Access denial was indicated as being able to retard or stop development activities altogether. When Landmines restrict access to arable or pastoral lands, the people who depended on those lands are pushed to use or abuse marginal resources, or move into refugee camps or urban centres, depending on the availability of alternatives. Moreover, declining availability of land was found to increase the need for practicing more intensive agricultural production systems that rely on heavy application of mechanical, chemical or biological supplements for production on the safe land. At the most basic levels, some of the ways these practices could endanger the health of the soil include:

1. Rapid exhaustion of the soil's mineral nutrient stock due to continuous cultivation with no fallow or rotations;

2. Mechanically intensive agriculture and

3. Excessive uses of chemical supplements and their consequent accumulation in the ecosystem. On the other hand, access denial has been observed to have 'positive' effects when the mined areas become 'no-man's land'. It is that, during limited anthropogenic interference flora and fauna get a chance to 
flourish and recover. Formerly arable and pasture lands in Nicaragua were turned into forest and forests remained undisturbed after the introduction of landmines. However, it need to be pointed out that, these benefits would only last as long as animals or tree roots do not detonate the mines. In addition, in land of lesser quality, long fallow periods could potentially end up creating or exacerbating loss of productivity.

\section{Loss of biodiversity}

The impact of landmines on different plant and animal populations is considered to be a foremost environmental concern, next to access denial. As long as they receive enough mass to activate those landmines do not differentiate between human beings or other life forms. Landmines can threaten biodiversity in a given region by destroying vegetation cover during explosions or demining, and when animals fall victim. Landmines pose an extra burden for threatened and endangered species. Landmines have been blamed for pushing various species to the brink of extinction. Although it is widely believed that landmines destroy vegetation and kill untold numbers of animals every year, this is unfortunately one of the areas where there is hardly any numerical data to determine how many individuals of a species or where and how they fall victims. The very little data that exists on animal population is also highly biased towards domesticated animal and little is known about the impacts suffered by wild populations.

Some of the animals that regularly fall victim to Landmines include brown bears in Croatia; barking bear, clouded leopard, snow leopard and royal Bengal tigers and Kashmiri stag (Hangul) in J\&K (India) and gazelles in Libya. Landmines are accused of threatening extinction of elephants in parts of Africa and in Sri Lanka, and leopards in Afghanistan. Additionally, almost four percent of the very rare European brown bears were reported killed by landmines in Croatia between 1991 and 1994 alone. Mines have killed one of the very few remaining mature, male silver backed mountain gorillas in Rwanda and virtually eradicated gazelles from Libya. With regards to domesticated animals, studied the social costs of Landmines in 206 communities in Afghanistan, Bosnia, Cambodia and Mozambique and reported that more than 57000 animals were killed due to landmines, over 35000 of which belonged to the Kuchi Nomads in Afghanistan. Another study also reported that more than 125000 camels, sheep, goats and cattle have been killed in Libya in between 1940-1980. Many of the biodiversity loss hotspots of the world are severely affected by landmines. Nacho'n referred to biodiversity data from the World Conservation Monitoring Centre and identified a large number of species that are threatened or endangered due to many factors, including the presence of landmines in their habitat or migratory paths. Moreover, landmines are used for poaching endangered species of wildlife, and refugees and IDP further contribute to loss of biodiversity when they hunt animals for food or when they destroy their habitat in order to make shelters for themselves.

Landmine impacts on plants are even less documented. Landmines affect plant populations by causing slow-death of trees when they sustain shrapnel injuries or abrasions of their bark or roots when fragmentation mines detonate, providing an entry site for wood-rotting fungi. In regions where arable and pastoral activities turn out to be impossible due to landmines, forests become the last resort for food, fuel wood and shelter. Valuable forest products, including fruits and timber, from previously avoided sensitive, endangered ecosystems are exploited by affected populations looking to start new livelihood somewhere else. Moreover, wood destined for lumber becomes unsafe and troublesome when metal fragments are embedded in it. Demining activities also influence biodiversity in many ways. Domesticated animals are frequently used for mine clearance purposes, especially dogs, sheep and cattle. These animals are let loose in minefields as easy and fast means of clearance. Furthermore, demining operations demand clearing all the vegetative cover, including forests from mine suspected areas, usually by using fire. The result is removal of litter that plays crucial roles in infiltration, protecting soil from erosion and the impact of rain drops, and providing organic matter that is important to biota and stability of soil's structure.

\section{Micro-relief disruption}

Landmine detonation causes damage to the soils' stability by shattering the soil structure, and causing local compaction, and increasing the susceptibility of soil to erosion. Deterioration of soil structure due to explosion, compaction or burning can be a slow and insidious progression, but their combination results in long term changes that have significant, sustained impacts on moisture availability, erodibility and productivity of the land. When a $250 \mathrm{gm}$ APL detonates, it can create a crater with a diameter of approximately $30 \mathrm{~cm}$. The explosion is described as having the ability to facilitate removal and displacement of topsoil while forming a raised circumference around the crater and compaction of soil into the side of the crater. The level of the impact can vary depending on the physical conditions of the soil; the type and composition of the explosive and how many landmines detonate in the vicinity. The impact is greater in dry, loosely compacted and exposed desert soils but is less severe in humid soils that have vegetation or physical protection. Susceptibility to reduced infiltration, flooding and erosion is also higher in areas with steep slopes. In such cases, transported soil increases sediment load of drainage systems. When soil is compacted due to external forces, its resistance to 
penetration by plant roots and emerging seedlings increases, the exchange of oxygen and carbon dioxide between the root zone of plants and the atmosphere is also retarded. Generally, as long as repeated explosions do not occur in the same location, the crater can develop into a stable element of the landscape when runoff or wind erosion washes soil to its bottom. In warm and humid regions, however, it has been reported that the crater may hold water, turn into a marsh and serve as breeding ground for mosquitoes. Around 20 percent of the respondents highlighted that demining activities result in micro-relief disruption by affecting the soil's biochemical and physical quality. A particularly harmful practice reported after the Gulf War is the use of fuel explosive bombs. These bombs are dropped from the sky, creating heavy shock-waves that are propagated into the ground seeking to cause buried landmines to detonate. In addition, a lot of organic pollutants get into the soil during this aerial demining process. Fires are used to facilitate demining, thus modifying the amount, form and distribution of biomass, organic matter and essential nutrients with in the soil profile. The high temperature of burning causes more rapid than 'normal' humus loss. Similarly, the temperature increase can cause $\mathrm{pH}$ of soil to become more alkaline and nutrient elements may be converted into more bio-available forms, or are lost from the soil by volatilization into the atmosphere, and transfer of ash with water or wind erosion.

\section{Chemical contamination}

Landmines interfere with the ability of the soil system to serve as a geochemical sink for contaminants. Depending on density of mines per unit area; the type and composition of the mine; and the length, amount and degree of exposure of resources to the mines, landmines can pose a serious pollutions threat, accumulation of non-biodegradable toxic waste of casings or unexploded remnants. Moreover, after conflicts, many regions are left with a massive volume of exploded and UXO that ruin the aesthetic quality of the area. Landmines are made of metal, timber or plastic casing and are filled with 2,4,6 Tri-nitrotoluene (TNT), Hexahydro1,3,5trinitro 1,3,5 triazine (RDX or Cyclonite). Landmines can also introduce other non-biodegradable and toxic waste, such as depleted uranium. These compounds have been known to leach into soil and underground water as cosing of the mines disintegrates. Specific contaminants have unique consequences the effect depends on many complex factors. In laboratory experiments with rats, TNT and RDX were found to be carcinogenic, causing tumours' in the bladder and male reproductive systems, and congenital defects, skin irritation, and disruption of the immunological system.

Landmines, to a lesser extent, also contain additional compounds including iron, manganese, zinc, chromium, cadmium, nickel, copper, lead and mercury, of which iron, manganese, zinc, copper and nickel are essential micronutrients in the plant soil system. Soil contamination with heavy metals is observed in areas surrounding mines when the mines decay or explode. In extreme cases, contaminations can be detected in as much as $6 \mathrm{Km}$ from the site of an explosion. Even higher concentrations of the heavy metals are found at the centre of the explosion site. Many of the organic and inorganic substances and compounds that are derived from the explosives are long lasting, water-soluble and toxic even in small amounts. The contamination can be delivered directly or indirectly into soil, water bodies, microorganisms and plants with drinking water, food products or during respiration.

These pollutant compounds can leach into subterranean waters and bio-accumulate in the organs of land animals, fish and plants. Their effects can be mortal to some mammals and aquatic macro and microorganisms by acting as a nerve poison to hamper growth. A significant landmine related chemical contamination threat is lead toxicity. Lead can have continuum of toxicity, meaning it can be harmful even at very small amounts, and its effects rise with increasing concentration. In human beings lead $(\mathrm{Pb})$ toxicity can result in kidney damage, sterility, miscarriage, and birth defects. Moreover, high levels of mercury (Hg) can result in neurological disorder; while cadmium (Cd) can cause kidney failure and Osteomalacia softening of bones and multiple bone fracture.

\section{Loss of productivity}

Landmines affect resource productivity whether they have detonated or not. Low availability of land (access denial), degradation of the soil (micro-relief disruption, chemical contamination), combined with loss of flora and fauna diversity add up to land degradation reduction in productivity of previously productive land.

Landmines have restricted agricultural production on a land area equivalent to 6 percent of the 1474 million ha of land cultivated globally. Landmines for being partly responsible for decreased agricultural productivity and lowered food security in mine affected countries. In 2000, it was reported that in the absence of the landmine crisis the productivity in Afghanistan could have increase by 88-200 percent, 135 percent in Cambodia, 11 percent in Bosnia and 36 percent in Mozambique compared to pre-war levels.

As agricultural and other important lands are taken out of production, the socio-economic state of affairs of the segments of population that were once self sufficient suffers. When people cannot get access to their land resources because it is no longer safe to enter a whole host of problems are created. Land degradation leads to many complex socio-politico-economic problems, including but not limited to, exploitation of available 
resources beyond their ecological carrying capacity, unemployment, poverty, social marginalization, desperation, and aid dependency.

\section{Socio-politico and Economic Dimensions of the Ecological Crisis}

Generally, the socio-politico-economic dimensions of the landmine problem as those that affect or result in community health, poverty, social marginalization and aid dependency, especially in developing nations that have limited resources and capacity to deal with calamity, landmine effects are experienced in environments already experiencing effects of wars, unfavourable climatic and economic conditions, and governments' uncertain commitment to the environment. It is essential to note that, even without the additional burden of landmines, $70000 \mathrm{~km}^{2}$ of farmland, which is mostly in the developing world, is abandoned because of ecologically degrading factors such as exploitative agriculture, deforestation, overgrazing and so on.

\section{Community health}

Long after the troops have withdrawn and all the guns have been silenced 'landmines remain in the ground as brutal reminders that successful peace building and development are still beyond the horizon.' Landmines cannot be recalled by the military when a ceasefire is declared. Each and every mine must be individually disarmed or destroyed. Even decades after cease-fire children, farmers, nomads, herders, returning refugees and IDPs continue to fall victims to landmines when the only choices they have are:

1. Take no risk and starve or

2. Risk deaths while trying to survive

In the absence of coordinated mine clearance operations, desperation causes communities to employ their own means of risk assessment that is mostly based on rumours or local knowledge.

As a result, 100 percent of peacetime victims are civilians, compared to 90 percent overall. Children face a particular risk because of their limited vision of the ground ahead and because of their tendency to mistake landmines for toys. These realizations cause psychological trauma and keep populations in a state of persistent fear that is manifested by refusal to cultivate their fields, and to return to their homelands. Furthermore, continued militarization of former battlegrounds and denial of access to resources have been observed to perpetuate power struggles and cause even more conflicts.

\section{Poverty and Social Marginalization}

Landmines are weapons of social cataclysm that have a subtle multiplier effect with the ability to drain societies' resource potential and bring misery for generations. The danger created by landmines frequently makes subsistence and sustainable development difficult, if not impossible. Landmines contribute to perpetuations of underdevelopment by killing or injuring a community's sources of income, inhibiting effective cultivation or control of pests and scaring away tourism and other means of income. Most landmine victims are adult men, the bread earners and heads of households.

The loss of more than 57000 animals due to landmines is equivalent to a minimum annual market value of roughly US \$200 per household. It is assumed that Afghanistan, Bosnia, Cambodia and Mozambique alone have suffered more than 6 million US dollars loss due to landmine's effect on animals. For the nomadic populations in North and Eastern Africa and the West Asia loss livestock reared for production of dairy, meat, leather products or subsistence farming activities have had significant socio-economic effects. At a larger scale, and mines and their impacts become added burdens to the already overtaxed economies and over stretched resource bases of struggling nations. Fragile financial systems of developing nations become more susceptible to failure as funds are diverted away from development, to take care of disproportionate health bills of victims. Landmines interfere with economic development.

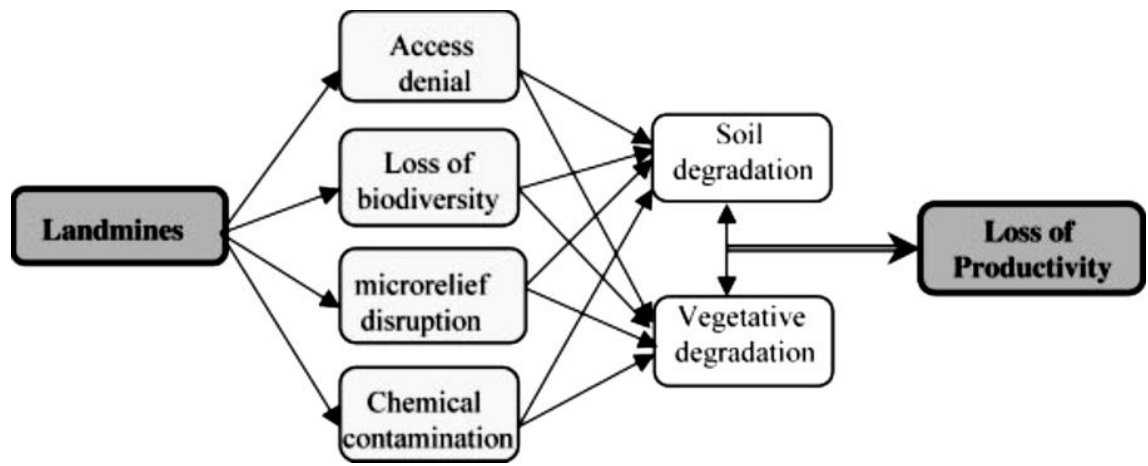

Figure 1: Compounding of landmine effects to result in loss of productivity and associated socio-politicoecological problems. 


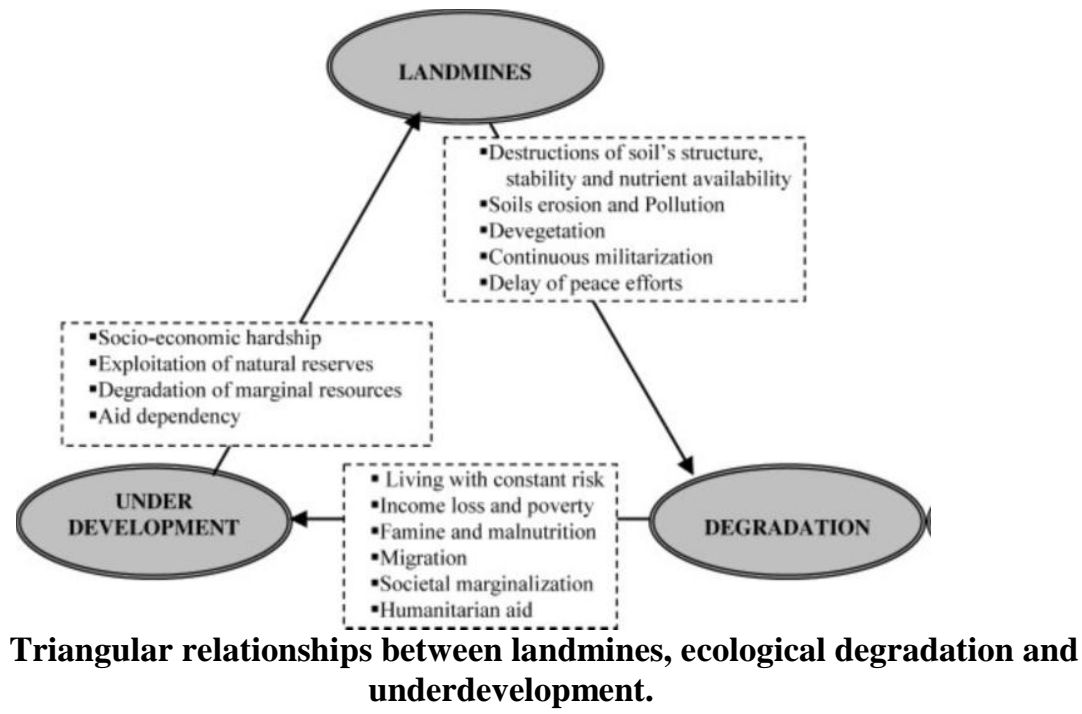

Landmines in Vietnam hindered the construction of a new major North-South highway, while demining activities drained the resources of the community in Mozambique to the point that there were no funds left to restore de-mined roads. Furthermore, with growing land scarcity the poor, women and minorities are disadvantaged.

\section{Aid Dependency}

When the land becomes off-limits or disrupted and its productivity is reduced the rural, subsistence populations are forced to live with aid from different humanitarian institutions. International aid for landmine assistance is critical, but when it is ineffectively handled it has the capacity to inadvertently cause more harm than good by undermining local strengths and endorsing aid dependency. Fear of returning to previously mined areas along with an unhealthy dose of aid dependency created problems of under reporting in Mozambique, while efforts were made by communities in Cambodia in an attempt to delay the departure of demining teams. Some field researchers also reported similar events where demined communities have been accused of laying new mines in order to attract other mine action programmes to their areas. It is plausible to point out that repeated problems of such kind can lead to donor fatigue, in which case the affected communities would be left to fend for themselves.

\section{Sustainable Development in the Aftermath of Landmine Crisis}

Combined effects of landmines have tremendous influence on development activities. Narrating the rhetoric of how environment and development are particularly interweaved in a cause and effect chain becomes particularly necessary here because this linkage puts Landmines, ecological degradation and underdevelopment in a triangular relationship. Land degradation occurs as a result of complicated feedbacks, while consequent underdevelopment causes simultaneous degradation of societies and their natural resources. The triangular representation (Fig.2) demonstrates the complexity of the environmental effects of landmines and shows how the variables in the different corners of the triangle are related to each other, and can lead to a vicious cycle of destruction.

To describe the causal link of landmine induced land degradation with development one can give the examples of deforestation and landmine effects on animal migration. Deforestation has been accelerated by extensive use of landmines. Where arable and pasture lands have been mined to such a degree that forests become the only source of livelihood, the long term consequences of selling old forests and fruit trees gives way to immediate survival pressures. Cascading effects from deforestation can affect the surrounding areas. Moreover, minefields in migratory paths of some terrestrial animals can cause more harm than just death or injury. As it is noted that after a large number of elephants perished in the minefield of Southeast Asia, others learned to avoid that area, instead moving into agricultural areas they previously avoided causing crop damage along their newly acquired migratory paths, which has led to local people hunting the animals to prevent further damage.

This landmine induced cycle of degradation continues by triggering socio-economic problems including loss of income, poverty, migration, and social marginalization of affected populations. Communities usually receive international humanitarian aid for demining and rehabilitation. But if the aid is provided in ways that fail to consider the real causes of the problem and the needs of the society it has tendency to foster aid dependency. In more extreme situations, landmines then drive populations to mine cleared areas in order to 
attract aid, or resource limitations leads to conflicts that reintroduce mines to the area, thus maintaining the triangular link between landmines, ecological degradation and underdevelopment. In most cases, land users and managers are aware of the inherent potentials and constraints of their land, and they do develop appropriate systems of management that suit the quality of their resources. However, when these populations are forced to move to other areas their traditional resource management systems can become unsuitable or inadequate leading to inappropriate land use (excessively intensive cultivation, overgrazing and deforestation in the mine free lands). Moreover, refugee populations usually have the dream of returning home and the settlement areas are perceived to be temporary; they strive to make the best out of the time they stay there. Refugee populations, more often than not, do not consider long term investments or the effects they have. Desperation, not ignorance or stupidity, leads to abandonment of rational, sound resource management bringing about a collective disorder tragedy of the commons. Regardless of who laid the mines and for what purpose they were placed, landmines promise to be impediments to development for a long time to come. Landmines change the natural environment in so many ways and make it hard, if not entirely impossible, for societies to achieve sustainable development that they might otherwise have attained.

Landmines cause multifaceted and interconnected ecological and socio-politico-economic problems. Landmine use is at best unchivalrous, but is a practical necessity. Landmines threaten the fragility of the natural environment by changing the quality and cover of land, and through abuse of biotic resources and habitat destruction. Landmines pose lose-lose situation because they will cause land degradation whether landmines are left in the ground or detonated. Moreover, it is clear that there can be no blueprint for sustainable development in mine affected regions.

\section{Conclusion}

Landmines are devastating to all level of society i.e. individual, family, community, and nation. The social-economic and other humanitarian impact of landmines have outweighed their military utility in warfare. They tear up the social fabric of nation, threatening not only to present but also the future generation. They hinder the development process, leads to loss of biodiversity, soil contamination and threat to survival by denying access to the resources. Landmines utility can in no way be justified because of their everlasting and indiscriminate nature. They pose grave threat to sustainable development and thereby to future generation. Landmines cause multifaceted and interconnected ecological and socio-politico-economic problems. Landmines threaten the fragility of the natural environment by changing the quality and cover of land, and abuse of biotic resources and habitat destruction. Landmines pose a lose-lose situation because they will cause land degradation whether they are buried in the ground or detonated. Therefore, it is clear that there can be no blueprint for sustainable development in mine affected regions. Demining is pre-requisite for development of mine contaminated areas and signing the Ottawa treaty is a step towards sustainable development in mine affected areas.

\section{References}

[1] Landmine Monitor Report 1999, "Humanitarian Mine Action” Accessed at http://www.icbl.org.

[2] J.Marshall Beier, "Sitting Indiscriminacy: India and the Global Movement to Ban Landmines," Global Governance, Vol. 8, No. 3: 305-321, July-September 2002 http://www.jstor.org/ stable/27800347

[3] Andersson N, da Sousa CP, Paredes S. 1995. "Social cost of land mines in four countries: Afghanistan, Bosnia, Cambodia, and Mozambique," British Medical Journal, Vol. 311, pp.71- 721.

[4] Ibid.

[5] Peterlik Karl, "Working Without Illusion: Key Note Address," in Christopher S Raj (ed.), Stalking Terror: Landmines in Peace and War, Delhi: Words smiths, 2000, p.55.

[6] Bob Eaton, "Crisis, Containment and Development: The Role of the Landmine Impact Survey," Third World Quarterly, Vol. 24, No. 5, October 2003, pp.909- 921, Available at http://www.jstor.org/stable/3993649.

[7] Buenker MA, "Landmines: A Threat to Wildlife and Sustainability," World Conservation, Vol. 1, pp.19-20.

[8] Andersson N, da Sousa CP, Paredes S. 1995, "Social Cost of Landmines in Four Countries: Afghanistan, Bosnia, Cambodia, and Mozambique", British Medical Journal, Vol.311, pp. 718-721.

[9] Claudio Torres Nachon, "The Environmental Impact of Landmines" in Richard A Mathew, Bryan MC Donald, Kenneth R Rutherford (ed.) Landmines and Human Security: International Politics and War Hidden Legacy, State University of New York press Albany, pp.191-204.

[10] A. A. Berhe, "The Contribution of Landmine to Land Degradation," Land Degradation Development, Vol. 18, pp.115, 2007, Available at http://www.interscience.wiley.com.

[11] Ibid.

[12] International Physicians for the Protection of Nuclear War, "Landmine Fact in Brief," Available at http://www.ippnw.org/MineFacts.html.

[13] A. A. Berhe, "The contribution of Landmine to Land Degradation," Land Degradation Development, Vo18, pp.1-15, 2007.

[15] Jeffery V Rosenfeld, "Landmines: The Human Cost ADF Health,” Vol. 1, No.1, pp.93-98, September 2000.

[16] A. A. Berhe, The Contribution of Landmine to Land Degradation, Land Degradation Development, Vol.18, pp. 1-15, 2007.

[17] Andersson N, da Sousa CP, Paredes S. 1995. "Social cost of land mines in four countries: Afghanistan, Bosnia, Cambodia, and Mozambique," British Medical Journal, Vol. 311, pp.71- 721.

[18] Jody Williams, "Landmines: A Global Socioeconomic Crisis," Social Justice, Winter 1995, p.97.

[19] Eoin O'Brien, "Clearing the Killing fields", Journal of the Royal College of Physicians of London, Vol.29, No.4, July- August 1999.

[20] A. A. Berhe, "The contribution of landmine to land degradation," Land Degradation Development, Vol. 18, pp. 1-15, 2007, Available at http://www.intersciencewiley.com 